\title{
A (IN)EFICÁCIA DOS SELOS VERDES SOBRE O COMPORTAMENTO DOS CONSUMIDORES: um estudo experimental
}

\section{1- Taís Pasquotto Andreoli*}

Doutoranda em Administração pela Universidade Municipal de São Caetano do Sul (USCS), Brasil.

Programa de Pós-Graduação em Administração - Universidade Municipal de São Caetano do Sul (PPGA/USCS), Brasil. tais_pa@hotmail.com

http://lattes.cnpq.br/4402149857270524

\section{2- Váldeson Amaro Lima}

Doutorando em Administração pela Universidade Municipal de São Caetano do Sul (USCS), Brasil.

Programa de Pós-Graduação em Administração - Universidade Municipal de São Caetano do Sul (PPGA/USCS), Brasil. Professor EBTT de Administração no Instituto Federal de Educação, Ciência e Tecnologia de Rondônia (IFRO), Brasil. valdeson.lima@ifro.edu.br http://lattes.cnpq.br/2186520755838978

\section{3- Leandro Campi Prearo}

Doutor em Administração pela Universidade de São Paulo (FEA/USP), Brasil.

Professor no Programa de Pós-Graduação em Administração - Universidade Municipal de São Caetano do Sul (PPGA/USCS), Brasil.

leandro.prearo@uscs.edu.br

http://lattes.cnpq.br/5069741934577746

\section{Diego Maganhotto Coraiola - Editor Geral}

\author{
Editor responsável pela submissão: \\ Diego Maganhotto Coraiola. \\ Artigo analisado via processo de revisão duplo cego (Double-blind). \\ Recebido em: 25/02/2017 \\ Aprovado em: 27/04/2017 \\ última Alteração: 04/08/2017
}

* Contato Principal: Rua Santo Antônio, 50, Centro, São Caetano do Sul - SP, Brasil. CEP: 09521-160 
A (IN)EFICÁCIA DOS SELOS VERDES SOBRE O COMPORTAMENTO DOS CONSUMIDORES: UM ESTUDO EXPERIMENTAL ${ }^{1}$

\title{
RESUMO
}

O trabalho teve como objetivo analisar a percepção dos consumidores acerca dos selos verdes, de acordo com quão conhecidos esses selos são e segundo seu próprio perfil de consumo verde. Sendo assim, elaborou-se um referencial teórico acerca do consumo sustentável, assim como sobre a aplicação dos selos verdes na perspectiva do marketing verde. O método adotado foi uma abordagem hipotético-dedutiva, realizada por meio de dois experimentos (um online e o outro presencial), ambos com desenho fatorial 2 (selo verde verdadeiro e bastante conhecido versus selo falso e nada conhecido) x 2 (consumidor com perfil muito sustentável versus pouco sustentável). Diante dos resultados obtidos, quatro principais discussões puderam ser levantadas, como a possibilidade de greenwashing decorrente da clara menção aos aspectos ambientais, seja em relação ao selo em si ou aos dizeres subjacentes a ele, a ineficácia da prática de adoção de selos verdes e a influência dessa ineficácia nos consumidores, inclusive naqueles que relataram possuir um perfil de consumo mais verde.

\section{Palavras-chave}

Consumo sustentável; Marketing verde; Selos verdes; Pesquisa experimental; Greenwashing.

\section{THE (IN)EFFECTIVENESS OF GREEN SEALS ON CONSUMER BEHAVIOR: A EXPERIMENTAL STUDY}

\begin{abstract}
The objective of the study was to analyze consumers' perceptions about green seals, according to how well known these seals are and to their own profile of green consumption. Therefore, a theoretical reference was made on sustainable consumption, as well as on the application of green seals in the perspective of green marketing. The method adopted was a hypothetical-deductive approach, carried out through two experiments (one online and the other face-to-face), both with factorial design 2 (true and well-known green seal versus false seal and nothing known) $\times 2$ very sustainable versus low sustainable consumer profile). In view of the results obtained, four main discussions could be made, such as the possibility of greenwashing due to the clear mention of environmental aspects, either in relation to the seal itself or to the statements underlying it, the ineffectiveness of adopting green seals and influence of this ineffectiveness even in consumers who reported having a more sustainable consumption profile.
\end{abstract}

\section{Keywords}

Sustainable consumption; Green marketing; Green seals; Experimental research; Greenwashing. 


\section{Introdução}

As questões relacionadas às mudanças ambientais e suas possíveis consequências trazem à tona uma série de discussões, impulsionadas principalmente pela realização de diversos congressos internacionais. Essas discussões estendem-se também em meio à sociedade, que se mostra cada vez mais preocupada, não só com a questão ambiental de uma maneira geral, mas também com seu papel nessa problemática.

Como consequência, essa preocupação acaba refletindo também no âmbito organizacional, em especial sobre o consumo. Dessa forma, encontra-se legitimada no conhecimento científico, a partir de diferentes estudos (Braga Junior, Silva \& Moretti, 2011; Silva, 2012; Côrtes \& Moretti, 2013), a ideia de que os consumidores estão cada vez mais conscientes acerca da problemática ambiental, preocupando-se mais sobre como o consumo - individual ou coletivo, direto ou indireto - contribui para melhorar ou piorar esse cenário.

A emergência do consumo sustentável e suas variantes (consumo verde, consumo responsável, consumo consciente, consumo ético etc.) contribuiu para que houvesse uma mudança no comportamento dos consumidores, que passam a ser mais críticos em relação não só ao padrão de escolha de produtos, mas também em relação aos seus hábitos de consumo, assim como em relação às ações realizadas e propagadas pelas organizações que adotam como estratégia os apelos de preservação do meio ambiente.

Nesse contexto, é esperado das organizações reação frente a essas novas demandas do mercado, sendo impelidas a buscarem novas estratégias de marketing no intuito de criar uma proposição de valor, que englobe também a responsabilidade socioambiental. Conota-se assim, o conceito de marketing verde, cuja filosofia está pautada por ações que considerem a preocupação ambiental, abarcando o respeito à sociedade como um todo através das ações de preservação do meio ambiente (Andreoli, Crespo \& Minciotti, 2016).

Uma das principais ações de comunicação do marketing verde decorre do uso de selos de certificação ambiental, concedidos por programas de rotulagem ambiental, comumente chamados de selos verdes. Os selos verdes consistem, assim, em uma acreditação da qualidade ecológica e/ou socioambiental de determinado produto, concedido mediante a exigência de comprovações periódicas por parte das organizações.

De acordo com Côrtes e Moretti (2013), o consumo verde é uma resposta às preocupações ambientais que repercute nas estratégias de marketing que podem ser adotadas pelas empresas, ao mesmo tempo em que o trabalho de Paço, Alves, Shiel, e Leal Filho (2013) identificou correlações entre iniciativas pró-ambientais desenvolvidas pelas empresas e a intenção de compra por parte dos consumidores.

Nesse cenário, assumindo como pressuposto que a adoção de práticas de marketing como os selos verdes podem influenciar na decisão de compra dos consumidores, o presente trabalho teve como objetivo analisar a percepção dos consumidores acerca dos selos verdes de acordo com quão conhecidos esses selos são e segundo seu próprio perfil de consumo verde. Com isso, espera-se contribuir na discussão acerca do consumo verde e no comportamento dos consumidores em relação às práticas de marketing verde pelas organizações, especialmente acerca dos selos ambientais (selos verdes).

\section{Consumo Verde ou Sustentável?}

As sociedades têm perseguido hábitos de consumo mais sustentáveis desde as décadas de 1960 e 1970, principalmente quando a publicação do livro Silent Spring (Carson, 1962) impulsionou o surgimento de diversos movimentos ecológicos que passaram a suscitar com maior intensidade questionamentos sociais sobre o consumo e seus impactos ambientais (Pereira \& Ayrosa, 2004; Deus, Felizola \& Silva, 2010).

Ainda que a publicação de Carson (1962) tivesse direcionamento para a indústria química e o impacto do uso de pesticidas sobre o comportamento de espécies animais, especialmente das aves, sua obra tornou-se referência mundial, suscitando ampla preocupação pública com a poluição ambiental e, posteriormente, sobre o consumo. Desde então, diversas pesquisas têm sido conduzidas no sentido de melhor compreender o comportamento de organizações e consumidores em relação ao consumo sustentável (Roberts, 1996; Bedante, 2004; Cabestré, Graziadei \& Polesel Filho, 2008; Côrtes \& Moretti, 2013; Joshi \& Rahman, 2015).

De acordo com Silva, Oliveira e Gómez (2013, p.176), o consumo sustentável ocupa o mais alto nível na hierarquização das práticas responsáveis de consumo, conceituado como "o padrão de 
consumo resultante de inter-relações sociais sob a perspectiva de interação política entre diferentes atores sociais direcionados ao alcance do desenvolvimento sustentável". Essa definição pressupõe a existência de tanto uma consciência individual, quanto uma atuação coletiva envolvendo a escolha de produtos sustentáveis, social e ambientalmente corretos. Nesse sentido, em consonância com o Instituto de Consumo Sustentável (2005), o consumo sustentável é exemplificado pela busca por produtos que utilizem menos recursos naturais em sua produção, que garantam o emprego decente aos que os produziram e que sejam facilmente reaproveitados ou reciclados, enfatizando, assim, uma visão mais holística sobre o processo produtivo, o ciclo de vida e o descarte de produtos.

Em uma perspectiva do consumo como um processo cultural (Slater, 2002; Assadourian, 2010; Silva, 2012; Silva \& Nascimento, 2015), Assadourian (2010), argumenta que o consumo sustentável permeia uma mudança de paradigma, de uma cultura de consumismo para uma cultura em que novos valores sociais estimulem apenas o consumo suficiente para a satisfação do bem-estar do ser humano. Concomitante a isso está uma maior atenção com os recursos naturais do planeta, tendo em vista a potencial extinção desses recursos se forem mantidos os atuais níveis de produção e consumo (Silva \& Nascimento, 2015).

Dessa forma, o consumo sustentável apresenta-se como uma resposta às preocupações ambientais (Côrtes \& Moretti, 2013), refletindo o momento cultural a qual a sociedade está inserida, perante as dinâmicas e demandas requeridas (Silva \& Nascimento, 2015), e redirecionando as tradições culturais no sentido da sustentabilidade (Assadourian, 2010). Esse novo paradigma de consumo exige do mercado e das empresas maior consciência dos impactos que suas ações e o consumo dos seus produtos causam ao indivíduo e a sociedade em longo prazo, visando garantir a satisfação das necessidades de consumo, de forma ética e responsável, porém apenas se consolida mediante uma mudança cognitiva e cultural (Silva, 2012).

Pode-se observar por essa discussão que o conceito de consumo sustentável é um tanto mais amplo e complexo que a interpretação comum atribuída ao termo como sendo o consumo de produtos sustentáveis ou ecologicamente corretos, que causem o mínimo de danos para o meio ambiente (Roberts, 1996; Silva \& Nascimento, 2015). Essa interpretação mais simplificada está mais próxima do conceito de consumo verde, que pode ser entendido, resumidamente, como a inclusão da variável ambiental na percepção de valor do produto pelo cliente no momento da compra, além das já tradicionais variáveis observáveis preço e qualidade (Silva, 2012; Braga Junior, Merlo \& Silva, 2016). Pode-se dizer que é um nível inferior de conscientização se comparado ao consumo sustentável, embora isso não diminua sua importante contribuição para a consolidação de uma mudança no perfil de consumo.

Diante desse cenário, os consumidores têm buscado cada vez mais organizações com imagem e reputação verde ou sustentável, que transmitam confiança e responsabilidade social e ambiental, obrigando, assim, uma evolução conceitual e mudança de paradigma (Silva \& Lopes, 2014). Nesse sentido, estudos têm demonstrado que grande parte dos consumidores já adota comportamentos de consumo sustentável (Afonso, Bornia, Echegaray \& Andrade, 2016), tendência que está em crescente ampliação (Deus, Felizola \& Silva, 2010). Além disso, foi observado também um aumento da importância atribuída à percepção de valor e da satisfação com o consumo de produtos verdes (Hur, Kim \& Park, 2013), bem como se evidenciou a existência de influência positiva do nível de consciência ambiental, tanto em relação às intenções de compra de produtos ecologicamente embalados, quanto referente às atitudes em relação ao consumo sustentável (Bedante, 2004).

Entretanto, apesar do crescente reconhecimento da importância dos problemas relativos ao padrão de consumo, argumenta-se que ainda não houve, por parte do consumidor, uma compreensão plena das implicações de seus atos de consumo, tanto no que se refere aos impactos no meio ambiente, como com relação ao seu poder de induzir e interferir na promoção do desenvolvimento sustentável (Pereira \& Ayrosa, 2004; Assadourian, 2010), ressaltando que ainda existe um longo caminho a ser percorrido (Silva \& Gómez, 2010). Com isso, o marketing verde deve reforçar as suas competências de comunicação para melhorar as intenções de compra dos consumidores em direção ao consumo sustentável, contribuindo para a sua consolidação.

Dados os limites conceituais apresentados entre consumo sustentável e consumo verde, o presente estudo se delimita a abordagem de consumo verde, visto que os instrumentos metodológicos utilizados e a análise dos selos verdes como objeto de estudo não permitem uma avaliação além da percepção de valor no momento da compra. 


\section{Marketing Verde e os Selos Verdes}

De acordo com alguns autores, como Peatti (2001), Lopes e Pacagnan (2014), e Katrandjiev (2016), a evolução do conceito de marketing verde aconteceu em quatro estágios subsequentes: embrionário, ecológico, verde e sustentável. O estágio embrionário, iniciado em 1950 e vigente até 1970, foi resultado da abordagem sistemática de Alderson (1957) sobre a interação dos sistemas de marketing com a sociedade e seus impactos sobre o meio ambiente.

O segundo estágio, denominado marketing ecológico e abrangendo o período de 1975 a 1989 , iniciou-se após a realização do primeiro workshop sobre marketing ecológico pela American Marketing Association (AMA). Como resultado desse evento, tem-se a publicação do primeiro livro acerca dessa temática, intitulado "Ecological Marketing", organizado por Henion e Kinnear (1976). Esse estágio se caracterizou principalmente pelo combate aos prejuízos ambientais decorrentes das atividades de produção e comercialização, porém ainda restrito a problemas específicos, tais como a poluição do ar, derramamentos de petróleo, aplicação de pesticidas, herbicidas, entre outros.

O terceiro estágio, de marketing verde, compreende o período de 1990 a 2000, caracterizandose pela tomada de iniciativas de proporções mais amplas, trazendo para a consciência das atividades de marketing problemas envolvendo a extinção de plantas e espécies animais, a destruição de ecossistemas específicos, a pobreza em países em desenvolvimento, entre outros. Assim, medidas foram adotadas tendo em vista a redução dos danos ambientais das atividades mercadológicas das organizações e de suas práticas em geral, mas também no intuito estratégico de se adotar essas iniciativas verdes como vantagens competitivas.

Como consequência, foram cunhadas definições para o marketing verde, como a proposta pela AMA (Henion \& Kinnear, 1976), de que o marketing verde consiste no "estudo dos aspectos positivos e negativos das atividades de marketing em relação à poluição, ao esgotamento de energia e ao esgotamento dos recursos não renováveis". Uma das definições mais aceitas é a defendida por Polonsky (1994), que amplia o conceito incorporando uma ampla gama de atividades relacionadas com o processo produtivo, desde a concepção do produto até a sua divulgação (Afonso, 2010; Paço, Raposo \& Leal Filho, 2009; Suki, 2013). O autor defende ainda que essas atividades sejam voltadas à satisfação dos desejos e necessidades dos consumidores, desde que essa satisfação ocorra com o mínimo de impacto negativo sobre o meio ambiente.

O quarto estágio, pós anos 2000, é denominado marketing sustentável, contemplando mudanças mais sérias e radicais na maneira de pensar e praticar o marketing. Norteia-se principalmente considerando-se como objetivo a superação completa dos efeitos ambientais negativos da produção e consumo, incluindo a construção de uma política de sustentabilidade com forte orientação para o futuro.

Dessa forma, pode-se observar que é notável o amadurecimento do pensamento de marketing ao longo dos tempos, sobre a perspectiva de como suas atividades podem influenciar o equilíbrio ecológico do planeta, saindo de questões pontuais para uma forma mais holística de encarar a questão.

Entretanto, deve-se ressaltar que nem todas as organizações se viram preparadas ou mesmos dispostas a adotar essa nova perspectiva de marketing de maneira profunda, ainda que mantivessem a busca por melhor competitividade. Dessa forma, na ânsia de buscar uma maior valorização perante o mercado consumidor, nesse novo cenário, algumas organizações acabaram apostando na divulgação de apelos ambientais que não necessariamente condissessem às suas práticas organizacionais (Budinsky \& Bryant, 2013; Andreoli, Crespo \& Minciotti, 2016). Ou seja, iniciou-se, no meio empresarial, o que se conceitua como greenwashing, um discurso mentiroso acerca da prática ambiental, sem que haja um respaldo prático (Antunes, Santos \& Hurtado, 2015).

Apesar disso, como consequência do amadurecimento e maior consciência do pensamento de marketing, uma das práticas mais comuns de comunicação do marketing verde é a adoção de programas de rotulagem ambiental para a concessão de selos de certificação ambiental, também conhecidos como selos verdes.

De acordo com Corrêa (1998), em um trabalho seminal sobre a rotulagem ambiental no Brasil, os programas de rotulagem ambiental têm origem em meados da década de 1940, sendo que os primeiros rótulos consistiam em etiquetas de advertência referentes aos efeitos negativos de determinado produto sobre a saúde e o meio ambiente, aplicados inicialmente por imposição legal em pesticidas, fungicidas e raticidas. Posteriormente, a partir da década de 1970, esses programas foram estendidos para outros produtos, inclusive de forma voluntária por parte das organizações. Esse advento ocorreu concomitante com a evolução da discussão acerca do marketing verde, assim como com o aumento da receptividade do mercado consumidor. 
Embora as etiquetas de advertência tenham sido o primeiro passo para a consolidação dos programas de rotulagem ambiental, os selos verdes não devem ser confundidos com os rótulos de advertência, com as autodeclarações de qualidades ambientais feitas pelos fabricantes ou mesmo com programas que verificam a conformidade do produto a apenas um requisito ambiental (como o selo PROCEL, por exemplo, que verifica o consumo de energia elétrica) (Corrêa, 1998). Esses exemplos são normalmente estabelecidos sem levar em consideração os diferentes impactos ambientais acarretados ao longo de todas as etapas do processo produtivo, inclusive no descarte final do produto, enquanto que os selos verdes têm obrigação de fazê-lo (Campanhol, Andrade \& Alves, 2003; Deus, Felizola \& Silva, 2010; Campos, Palma, Neutzling, Zucato \& Slongo, 2013).

Nesse sentido, Corrêa (1998) define os selos verdes como rótulos concedidos com base em critérios ambientais formulados a partir da análise do ciclo de vida do produto, cujo objetivo é informar os consumidores sobre o caráter ambientalmente favorável de determinados produtos. Em outras palavras, o selo verde consiste em uma acreditação da qualidade ecológica e/ou socioambiental de determinado produto, concedida para organizações que comprovam, por meio de avaliações periódicas, que seus ciclos de vida (desenvolvimento, produção, consumo e descarte) são amigáveis para o planeta e seus ecossistemas.

Em que pese a importância dos selos verdes como indicativos de processos produtivos sustentáveis em benefício da vida no planeta (Deus, Felizola \& Silva, 2010), os benefícios comerciais advindos de sua adoção ainda têm sido imperativos sobre a decisão das empresas em investir nisso e são relatados em diferentes estudos. Campos et al. (2013), por exemplo, mostram que a presença dos selos faz com que os consumidores avaliem de forma diferenciada a organização que o adota, levando tanto a uma melhor avaliação da identidade corporativa atrelada à questão ambiental, quanto aumentando a propensão de compra dos produtos rotulados.

Da mesma forma, uma série de outros estudos (Campanhol, Andrade \& Alves, 2003; Deus, Felizola \& Silva, 2010; Lopes \& Pacagnan, 2014; Guimarães, Viana \& Costa, 2015) evidenciam que os selos verdes têm servido para conquistar novos mercados e otimizar vendas, constituindo oportunidade estratégica e/ou vantagem competitiva para a organização que deseja agregar valor à sua imagem e se diferenciar de seus competidores no mercado. Por outro lado, a ausência dos selos em alguns setores produtivos constitui entraves adicionais ao comércio, assim como elimina a competitividade dos produtos (Corrêa, 1998).

Como resultado dessa discussão, espera-se que os consumidores de fato se preocupem e valorizem a questão da acreditação ambiental, notando a presença dos selos verdes nos produtos, assim como os reconhecendo e sabendo seus significados, especialmente se eles forem mais conhecidos e verdadeiros. Isso também deve ser verdadeiro para o perfil de consumo verde, com melhores resultados quando o perfil é muito verde, em detrimento de quando é pouco verde.

H1 - A percepção geral dos consumidores [ (a) lembrança de ter visto, (b) conhecimento e (c) saber o significado] é influenciada pela popularidade e veracidade dos selos.

H2 - A percepção geral dos consumidores [ (a) lembrança de ter visto, (b) conhecimento e (c) saber o significado] é influenciada pelo seu próprio perfil de consumo sustentável.

Além disso, a adoção de selos verdes influencia não só na avaliação dessa prática em geral, como também no julgamento da marca em relação a atributos verdes.

H3 - A adoção de selos verdes influencia em (a) uma melhor avaliação geral acerca dessa prática e (b) em uma melhor avaliação verde da marca que adota selo verde, especialmente quando o selo verde é popular e veraz.

A mesma expectativa se faz em relação ao consumo sustentável, esperando que haja uma maior valorização desses aspectos por parte dos consumidores com perfis mais sustentáveis, em detrimento daqueles com perfis menos sustentáveis.

H4 - O perfil de consumo sustentável influencia em (a) uma melhor avaliação geral acerca da prática de adoção de selos verdes e em (b) uma melhor avaliação verde da marca que adota selo verde, especialmente quando o perfil é bastante sustentável.

\section{Método}

O estudo se caracterizou por uma abordagem hipotético-dedutiva, com foco na validade interna dos resultados. O desenho fatorial adotado foi 2 (selo verde verdadeiro e bastante conhecido 
versus selos falso e nada conhecido) x 2 (consumidor com perfil muito sustentável versus pouco sustentável). A primeira variável dependente foi estipulada de acordo com o quão conhecido o selo verde era, adotando o selo FSC (Forest Stewardship Council, primeiro selo verde da história, mundialmente utilizado, adotado em mais de 75 países) como o verdadeiro e bastante conhecido, e um selo falso como o nada conhecido, que impossibilita o conhecimento prévio dos participantes. Já a segunda variável foi mensurada segundo escala de consumo verde adaptada de Côrtes e Moretti (2013), com oito assertivas, que foi categorizada em termos de perfil pouco sustentável (relacionado ao primeiro quartil, valor até 5,13 ) e muito sustentável (referente ao terceiro quartil, valor acima de $7,84)$, descartando todos os demais resultados medianos.

O instrumento de pesquisa foi desenvolvido no sentido de analisar e comparar as lembranças e julgamentos dos participantes em relação aos selos adotados, cujas métricas aparecem melhor explicadas no subtópico referente ao questionário.

Foram realizados dois testes experimentais, ambos com o mesmo procedimento, que consistiu na apresentação de um produto (papel A4) cuja embalagem continha um dos selos supracitados, seguida da avaliação desse material pelos participantes. O material consistiu em uma adaptação da imagem divulgada pela marca ARO, cujo design está em consonância com as demais organizações atuantes nesse ramo, aumentando, entretanto, a evidência dada ao selo, modificando o tamanho da exposição do selo para quase $50 \%$ maior do que a original.

Em ambos os casos a amostra foi não probabilística, mas escolhida por conveniência e distribuída de forma aleatória entre os tratamentos, selecionando estudantes universitários como participantes, devido à tendência de se conseguir mais facilmente a homogeneidade entre os tratamentos. O teste de poder da amostra foi rodado nos dois estudos, por meio do programa Gpower, a fim de se validar o tamanho das amostras necessárias e assegurar a validade dos resultados obtidos com elas. Foram empregadas diferentes técnicas de análise de dados, não paramétricas e paramétricas, dependendo dos dados em questão. Para o desenvolvimento do instrumento de coleta de dados, foi rodada uma análise fatorial exploratória. Nos pré-testes de manipulações, foi rodado o teste de Wilcox (duas variáveis). Nos dados reais, nas análises unidimensionais, foram empregados o teste de Mann-Whitney $U$ e a ANOVA one-way enquanto que nas análises bidimensionais foram utilizados os testes de Kruskal Wallis e a ANOVA two-way. Também o teste não paramétrico de correlação de Spearman foi adotado, de maneira complementar.

\subsection{Questionário}

O questionário foi composto, inicialmente, por uma pergunta indagando acerca de três principais atributos que os participantes atribuiriam à marca exposta previamente, a fim de verificar se e quanto o apelo verde foi mencionado. Em seguida, haviam questões referentes à percepção geral dos consumidores acerca do selo exibido, como lembrança (se lembravam de ter visto e qual era o selo), conhecimento (nota para o quanto conheciam) e entendimento (se sabiam o que significava e o qual era o significado).

Em um segundo momento, após uma breve explicação do que consistiam os selos verdes, exemplificando com o selo em questão, foi apresentada uma escala com seis assertivas com julgamento em relação aos selos verdes em geral, para as quais os participantes deveriam atribuir uma nota de 0 a 10 de acordo com o seu grau de concordância, sendo 0 discordo totalmente e 10 concordo totalmente. As assertivas buscaram identificar a percepção dos consumidores em relação ao conhecimento acerca dos selos verdes, ao entendimento que os consumidores têm deles, à atenção que os selos verdes chamam, à confiabilidade dessas certificações, à possibilidade de confusão/engano, à influência na intenção de compra e à disposição de pagar a mais por um produto em virtude do selo verde.

Um pré-teste foi realizado com 27 participantes, rodando-se uma análise fatorial exploratória das respostas a sete assertivas iniciais relacionadas aos selos de certificação ambiental, avaliandose KMO, MSA, comunalidade e variância média extraída e, em função da necessidade de ajustes desses itens, foi eliminada uma assertiva, referente ao conhecimento que os consumidores têm em relação aos selos verdes. Em uma segunda rodada, todos os índices se ajustaram ao recomendado por Hair Jr. (2009), mantendo, assim, as seis assertivas, divididas em dois fatores, com três assertivas cada: um fator mais abrangente, referente ao comportamento do consumidor de forma geral, que inclui as assertivas acerca do entendimento, da atenção e da impossibilidade de confusão/engano; um fator mais específico, que diz respeito à postura do consumidor, em particular, que agrupa as assertivas relacionadas à confiabilidade, à influência na intenção de compra e à disposição de pagar mais por isso. 
O questionário continha, ainda, uma escala de consumo verde. Para tanto, utilizou-se um recorte da escala proposta por Côrtes e Moretti (2013, p.76), originalmente composta de 26 assertivas distribuídas em sete dimensões, que são: crenças (6), preocupação global (3), preocupação local (3), atitude global (3), atitude local (3), consumo potencial (4) e consumo real (4). Como a escala trata de questões mais gerais, relativas à preocupação ambiental como um todo e a influência de fatores transculturais sobre o comportamento de compra, para os fins deste estudo foram consideradas apenas as dimensões consumo potencial e consumo real, totalizando oito assertivas, visto que o objetivo do estudo está delimitado à influência dos selos sobre comportamento de consumo. A essas assertivas, também foi solicitado que os participantes atribuíssem uma nota de 0 a 10 de acordo com seu nível de concordância, sendo os extremos 0 discordo totalmente e 10 concordo totalmente.

Por fim, o questionário encerrou com questões referentes ao perfil dos participantes, como sexo, estado civil, idade, escolaridade, renda familiar e classe econômica.

Tabela 1:

Hipóteses e Métricas

\begin{tabular}{|c|c|}
\hline Hipóteses do Estudo & Questões \\
\hline $\begin{array}{l}\text { H1 - A percepção geral dos consumidores [ (a) lembrança de ter } \\
\text { visto, (b) conhecimento e (c) saber o significado] é influenciada } \\
\text { pela popularidade e veracidade dos selos } \\
\text { H2 - A percepção geral dos consumidores [ (a) lembrança de ter } \\
\text { visto, (b) conhecimento e } \\
\text { pelo seu saber o significado] é influenciada } \\
\text { pelo perfil de consumo sustentável. }\end{array}$ & $\begin{array}{l}\text { a) Lembra ter visto (sim/não) e } \\
\text { Evocação forçada (certo/errado) } \\
\text { b) Nota conhecimento (escala 0- } \\
\text { 10) } \\
\text { c) Sabe o que significa } \\
\text { (sim/não) e } \\
\text { Evocação forçada significado } \\
\text { (escala 1-4) }\end{array}$ \\
\hline $\begin{array}{l}\text { H3a - A adoção de selos verdes influencia em uma melhor } \\
\text { avaliação geral acerca dessa prática, especialmente quando o } \\
\text { selo verde é popular e veraz. } \\
\text { H4a - O perfil de consumo sustentável influencia uma melhor } \\
\text { avaliação geral acerca da prática de adoção de selos verdes, } \\
\text { especialmente quando o perfil é bastante sustentável. }\end{array}$ & $\begin{array}{l}\text { Avaliação geral da prática de } \\
\text { adoção de selos verdes (escala } \\
\text { de } 0 \text { a } 10, \text { com seis assertivas) }\end{array}$ \\
\hline $\begin{array}{l}\text { H3b - A adoção de selos verdes influencia em uma melhor } \\
\text { avaliação verde da marca que adota selo verde, especialmente } \\
\text { quando o selo verde é popular e veraz. } \\
\text { H4b - O perfil de consumo sustentável influencia em uma melhor } \\
\text { avaliação verde da marca que adota selo verde, especialmente } \\
\text { quando o perfil é bastante sustentável. }\end{array}$ & $\begin{array}{l}\text { Livre atribuição à marca } \\
\text { (menção verde ou não) }\end{array}$ \\
\hline
\end{tabular}

Fonte: Elaborado pelos autores.

\section{Apresentação dos Experimentos e Análise dos Dados}

A seguir, são apresentados os dois testes realizados, juntamente com os procedimentos específicos (materiais e pré-testes de manipulação) e resultados.

\subsection{Experimento 1}

Para o primeiro experimento, realizado de forma presencial, foram adotados os materiais expostos na Figura 1. Sendo assim, foi adotado como selo falso e nada conhecido o selo ElH, cuja sigla foi escolhida pelo sorteio aleatório de três primeiras letras.

Foi realizado um pré-teste $(n=83)$ para checar a manipulação acerca do conhecimento prévio dos selos, mensurado tanto por meio de uma questão nominal acerca de se conheciam cada um dos selos ou não, como uma escala de 0 a 10 referente à atribuição de nota para o nível de conhecimento acerca de cada selo, sendo 0 desconheço totalmente e 10 conheço totalmente. Ambas as questões encontraram diferenças significativas, verificadas por meio do teste não paramétrico de Wilcoxon. Diferença significativa também foi encontrada ao relacionar ambas as questões, ou seja, as notas dadas pelos participantes foram diferentes quando eles disseram que conheciam ou não cada um dos selos. Pode-se observar, assim, que esses resultados foram mais expressivos que no estudo anterior, garantindo maior validade à presente manipulação. 
Figura 1: Materiais utilizados

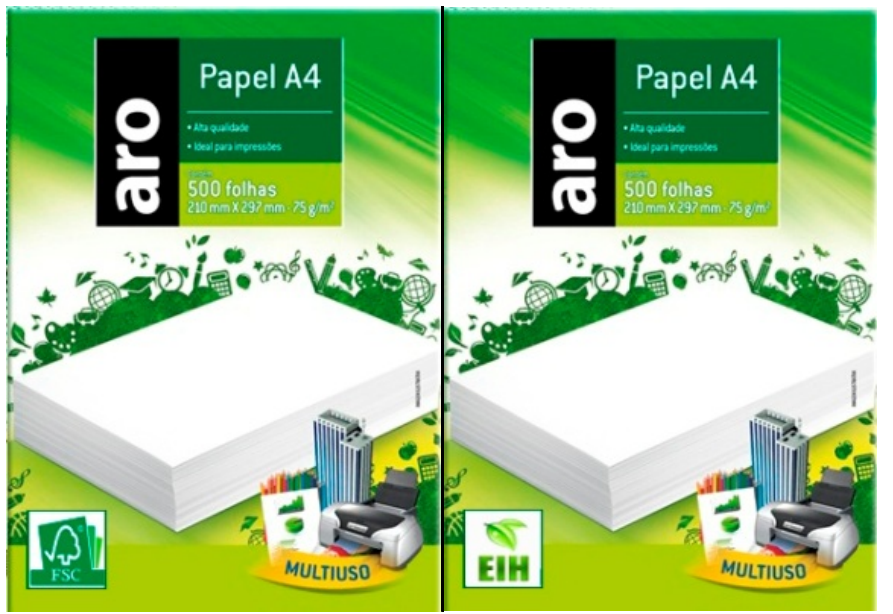

Fonte: Elaboração própria.

\subsubsection{Resultados e discussão}

Pelo teste de poder, a amostra $(n=72)$ apresenta um poder alto $(0,89)$, a um efeito de magnitude médio $(0,3)$ e um nível de significância de 5\%. A amostra se caracterizou por uma distribuição mais equilibrada entre os respondentes do sexo feminino (54\%) e sexo masculino (46\%), assim como entre solteiros (54\%) e casados (46\%), com idade média de 28 anos (variação entre 19 e 56). Em relação à renda, a maioria dos respondentes se concentrou entre uma renda familiar de até $R \$ 2.488(53,2 \%)$ e de $R \$ 2.489$ a $R \$ 6.220$ (35,5\%), com $11,3 \%$ participantes na faixa seguinte (de $R \$ 6.221$ a $R \$ 12.440$ ). A escolaridade da amostra é de ensino superior incompleto.

De uma maneira geral, houve um número maior de participantes que alegaram não se lembrar de ter visto os selos anteriormente $(57,1 \%)$, ante os que declararam se lembrar $(42,9 \%)$. Isso influenciou a capacidade de evocação forçada desses selos, que foram corretas em apenas $13,9 \%$ dos casos, contra $16,7 \%$ erradas e $69,4 \%$ sem resposta. As notas atribuídas ao nível de conhecimento dos selos variaram entre 0 e 10 , com média de 1,84 , com resultado semelhante às notas dadas para o quanto eles sabiam o que significam os selos, cuja média foi de 2,88 . Essas duas medidas se mostraram significativamente correlacionadas pelo teste não paramétrico de Spearman, de forma positiva e moderada $(S=0,467, p=0,000)$. Esses resultados foram reforçados pela baixa evocação forçada do significado, que tabulada em uma escala de 1 a 4 (variação entre realmente não sabe a realmente sabe), mostrou que apenas $13,9 \%$ dos participantes realmente sabiam a resposta e $34,7 \%$ estavam quase certos, contra $38,9 \%$ que realmente não sabiam a resposta e $12,5 \%$ que praticamente não sabiam.

Novamente, e de forma ainda mais expressiva, nota-se a baixa influência da exposição aos selos na percepção geral dos participantes, que não se lembram de tê-los visto e não conseguem evocá-los, assim como não os conhecem e nem sabem o que eles significam. Também a avaliação geral da prática de adoção de selos verdes não foi tão positiva como defendida pela literatura (Campos et al., 2013; Deus, Felizola \& Silva, 2010), cuja média ficou em 5,14, com variação de 0 a 10. Essa medida também apresentou correlação significativa com a nota de conhecimento, verificada pelo teste não paramétrico de Spearman, de forma positiva e fraca $(S=0,301, p=0,016)$.

Como consequência, também a sua prática como indicação de argumento ecológico pode ser colocada em xeque, já que apenas $26,4 \%$ dos participantes mencionaram algum aspecto verde como um dos principais atributos da marca. Cabe ressaltar que a questão acerca do atributo verde também poderia ter sido modificada, transformada em escala, o que se espera que provavelmente favoreceria a resposta positiva. Entretanto, optou-se por manter como pergunta aberta, visto que se acredita que assim seja a forma mais adequada de se averiguar a verdade.

A média geral de consumo sustentável, por sua vez, apresentou resultado variando de 2 a 10 , com média de 6,96, indicando, mais uma vez, possíveis mudanças comportamentais em relação à intenção de consumo mais consciente (Afonso, Bornia, Echegaray \& Andrade, 2016). Essa escala apresentou correlação significativa, positiva e moderada com a escala geral de julgamento dos selos, verificada por meio da correlação não paramétrica de Spearman $(S=0,505, p=0,000)$, endossando que, quanto mais consciente o indivíduo em relação ao perfil de consumo sustentável, maior a tendência de melhor julgamento acerca das práticas de adoção de selos verdes. 


\subsubsection{Análise unidimensional}

1) Não foi encontrada nenhuma diferença significativa em relação à manipulação do selo, comparando os selos FSC $(n=40)$ e EIH $(n=32)$.

2) Para verificar a influência do perfil de consumo sustentável, optou-se por categorizar esse perfil em pouco sustentável $(n=16)$ e muito sustentável $(n=18)$.

Apenas a escala geral de avaliação dos selos ( $\mathrm{H} 4 \mathrm{a})$ apresentou diferenças significativas entre os perfis, analisada por meio do teste paramétrico ANOVA $(F(1,34)=15,79, p=0,000)$, com uma melhor avaliação dos perfis muito sustentáveis $(M=6,22$, $D P=1,79)$ em comparação aos pouco sustentáveis $(M=3,71, D P=1,9)$. Ainda, a variável de perfil de consumo apresentou correlação significativa com a avaliação geral dos selos, identificada pela correlação de Spearman $(S=0,577$, $p=0,000$ ). Sendo assim, novamente, conforme esperado, o perfil sustentável influência na avaliação da prática de adoção de selos (suporte à $\mathrm{H} 4 \mathrm{a}$ ).

Tabela 2:

Teste de hipóteses - Análise unidimensional

\begin{tabular}{|l|c|c|}
\hline \multicolumn{1}{|c|}{ Hipóteses do Estudo } & Selo & Perfil \\
\hline $\begin{array}{l}\text { H1 - A percepção geral dos consumidores [ (a) lembrança de ter visto, } \\
\text { (b) conhecimento e (c) saber o significado] é influenciada pela } \\
\text { popularidade e veracidade dos selos }\end{array}$ & Não significativa & - \\
\hline $\begin{array}{l}\text { H2 - A percepção geral dos consumidores [ (a) lembrança de ter visto, } \\
\text { (b) conhecimento e (c) saber o significado] é influenciada pelo seu } \\
\text { próprio perfil de consumo sustentável. }\end{array}$ & - & Não significativa \\
\hline $\begin{array}{l}\text { H3a - A adoção de selos verdes influencia em uma melhor avaliaçãó } \\
\text { geral acerca dessa prática, especialmente quando o selo verde é } \\
\text { popular e veraz. }\end{array}$ & Não significativa & - \\
\hline $\begin{array}{l}\text { H3b - A adoção de selos verdes influencia em uma melhor avaliação } \\
\text { verde da marca que adota selo verde, especialmente quando o selo } \\
\text { verde é popular e veraz. }\end{array}$ & Não significativa & \\
\hline $\begin{array}{l}\text { H4a - O perfil de consumo sustentável influencia uma melhor avaliação } \\
\text { geral acerca da prática de adoção de selos verdes, especialmente } \\
\text { quando o perfil é bastante sustentável. }\end{array}$ & - & - \\
\hline $\begin{array}{l}\text { H4b - O perfil de consumo sustentável influencia em uma melhor } \\
\text { avaliação verde da marca que adota selo verde, especialmente quando } \\
\text { o perfil é bastante sustentável. }\end{array}$ & - & Não significativa \\
\hline
\end{tabular}

Fonte: Elaboração própria.

\subsubsection{Análise bidimensional}

Considerando a inexistência de diferenças significativas em relação à manipulação dos selos, esse resultado acabou impactando na manipulação dos perfis, no sentido de neutralizar sua influência. Sendo assim, não foram encontradas quaisquer diferenças significativas entre os quatro tratamentos em nenhuma das variáveis analisadas. Isso sugere que a fragilidade em relação à eficácia da adoção de selos verdes se torna ainda mais influente do que o perfil do consumidor sustentável, inclusive sendo capaz de anular sua influência.

Quadro 3:

Teste de hipóteses - Análise bidimensional

Hipóteses do Estudo

H1 - A percepção geral dos consumidores [ (a) lembrança de ter visto,

(b) conhecimento e (c) saber o significado] é influenciada pela popularidade e veracidade dos selos

H2 - A percepção geral dos consumidores [ (a) lembrança de ter visto, (b) conhecimento e (c) saber o significado] é influenciada pelo seu próprio perfil de consumo sustentável.

H3a - A adoção de selos verdes influencia em uma melhor avaliação geral acerca dessa prática, especialmente quando o selo verde é popular e veraz.

H3b - A adoção de selos verdes influencia em uma melhor avaliação verde da marca que adota selo verde, especialmente quando o selo verde é popular e veraz.

\begin{tabular}{|l|l|}
\hline Unidimensional & Bidimensional \\
\hline Não significativa & Não significativativa \\
\hline Não significativa & Não significativa \\
\hline Não signifificativa & Não significativa \\
\hline
\end{tabular}


Continuação..

H4a - O perfil de consumo sustentável influencia uma melhor avaliação geral acerca da prática de adoção de selos verdes, especialmente quando o perfil é bastante sustentável.

H4b - O perfil de consumo sustentável influencia em uma melhor avaliação verde da marca que adota selo verde, especialmente quando o perfil é bastante sustentável.

Fonte: Elaboração própria.

\subsection{Experimento 2}

Tendo em vista os resultados obtidos no primeiro experimento, algumas modificações foram realizadas e um segundo teste foi rodado, com os materiais expostos na Figura 2. Dessa forma, duas principais modificações foram efetuadas: primeiro, a substituição do selo falso e nada conhecida, do EIH para o ECO, que se espera que tenha maior apelo verde pela associação com o fator ecológico; segundo, adição do dizer "certificação ambiental" acima do selo, a fim de gerar maior evidência a ele.

Figura 2: Novos materiais utilizados
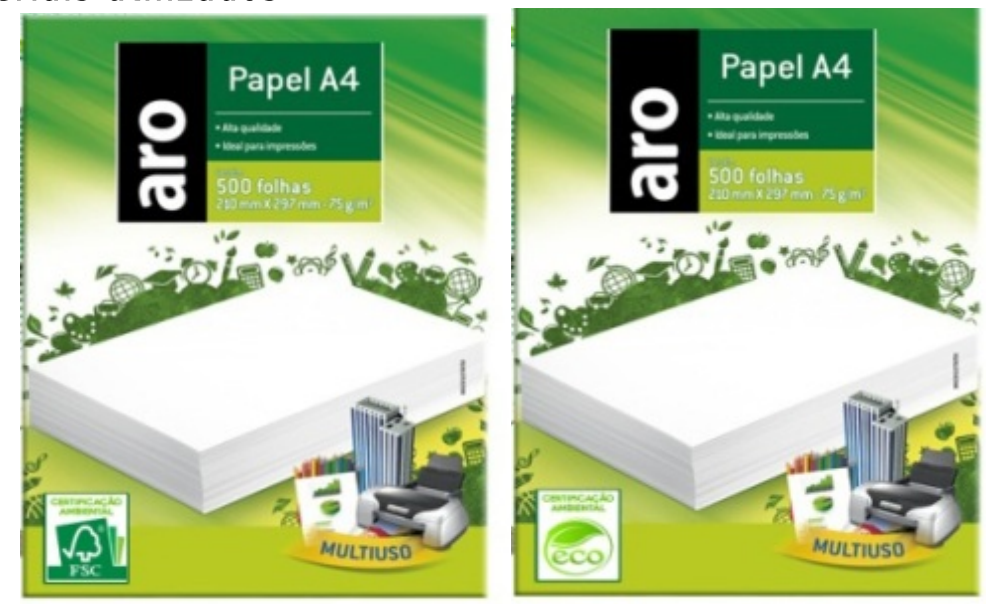

Fonte: Elaboração própria.

Foi realizado um pré-teste $(n=49)$ para checar a manipulação acerca da popularidade dos selos, mensurado por meio de uma questão solicitando a atribuição de uma nota de 0 a 10 para o nível de conhecimento acerca de cada selo, sendo 0 desconheço totalmente e 10 conheço totalmente. Essa questão encontrou diferenças significativas, verificadas por meio do teste não paramétrico de Wilcoxon. Além disso, foram analisadas possíveis diferenças entre as notas de conhecimento do selo segundo uma questão acerca de conhecê-lo ( $\mathrm{sim} / \mathrm{não}$ ), sendo que o teste não paramétrico de Wilcoxon indicou diferenças significativas para o selo FSC, mas não para o ECO. Ou seja, foram encontradas diferenças entre as notas dadas pelos participantes para o selo FSC quando eles disseram que conheciam ou não o selo, mas isso não se repetiu para o selo ECO. Dessa forma, pode-se dizer que esse resultado sugere que os participantes de fato conhecem mais o selo FSC, quando comparado ao selo ECO.

\subsubsection{Resultados e discussão}

Pelo teste de poder, a amostra $(n=138)$ apresenta um poder alto $(0,89)$, a um efeito de magnitude médio $(0,3)$ e um nível de significância de $5 \%$. A amostra se caracterizou por uma maioria de respondentes do sexo feminino $(63,4 \%)$, casados $(76,6 \%)$ e com idade média de 27 anos (variação entre 17 e 64). Em relação à renda, grande parte se concentrou entre uma renda familiar de até $R \$ 2.488(37,1 \%)$ e de $R \$ 2.489$ a $R \$ 6.220(45,2 \%)$, com $15,3 \%$ participantes na faixa seguinte (de $R \$ 6.221$ a $R \$ 12.440$ ) e apenas $2,4 \%$ acima disso. A escolaridade da amostra é alta, variando entre ensino superior incompleto (79\%) e completo (21\%).

De uma maneira geral, houve equilíbrio entre os participantes que alegaram se lembrar de ter visto os selos anteriormente $(44,2 \%)$ e os que não se lembraram $(55,8 \%)$. Isso influenciou a capacidade de evocação forçada desses selos, que foram corretas em apenas $12,3 \%$ dos casos, 
contra $46,4 \%$ erradas e $58,7 \%$ sem resposta. As notas atribuídas ao nível de conhecimento dos selos variaram entre 0 e 10, com média de 2,82. É interessante apontar que foi verificada uma correlação significativa positiva entre a lembrança de ter visto e a nota de conhecimento, ainda que fraca, verificada pela correlação não paramétrica de Spearman $(S=0,29, p=0,001)$. Apesar de $52 \%$ dos participantes terem afirmado que sabiam o que os selos significavam, quando a evocação do significado foi forçada, posteriormente tabulada em uma escala de 1 a 4 (variação entre realmente não sabe a realmente sabe), $58 \%$ dos participantes realmente não sabiam a resposta, assim como $15,2 \%$ também praticamente não sabiam. O acerto total foi de apenas $13,8 \%$ dos participantes, seguido de uma aproximação de acerto de $13 \%$.

Dessa forma, pôde-se observar que os consumidores não têm sua percepção geral do selo influenciada pela prévia exposição, não se lembrando do selo a qual foram expostos anteriormente, assim como não os conhecendo. Além disso, observou-se que, ainda que os participantes afirmassem saber o significado dos selos, a mensuração indicou que eles de fato não sabiam. Resultado semelhante se deu em relação à avaliação geral da prática de adoção de selos verdes, cuja média ficou em 5,32, com variação de 0 a 10.

Esse desconhecimento dos selos verdes já havia sido levantado anteriormente (Deus, Felizola \& Silva, 2010), indicando que os selos verdes aparentam não possuir tamanha valorização como defendido pela literatura (Campos et al., 2013; Deus, Felizola \& Silva, 2010). Os resultados sugerem a incapacidade dos selos em representarem de forma objetiva o critério de qualidade socioambiental esperado pelos consumidores no momento da compra (Deus, Felizola \& Silva, 2010), já que o sucesso de iniciativas de caráter ecológico depende do conhecimento e consciência do consumidor sobre o assunto (Campanhol, Andrade \& Alves, 2003).

Outrossim, se não existe conhecimento acerca dos selos verdes, é questionável a indicação de sua prática como argumento ecológico capaz de gerar oportunidade estratégica ou vantagem competitiva. Isso se mostrou verdadeiro ao analisar o aspecto verde atribuído à marca, visto que os resultados mostraram que apenas $33,3 \%$ dos participantes o mencionaram como um dos principais atributos da marca. Isso vai de encontro às afirmações encontradas na literatura, de que a presença dos selos faz com que os consumidores avaliem de forma diferenciada a organização que o adota, ou que percebem alguma agregação de valor à sua imagem no mercado (Campos et al., 2013; Campanhol, Andrade \& Alves, 2003; Deus, Felizola \& Silva, 2010; Lopes \& Pacagnan, 2014; Guimarães, Viana \& Costa, 2015). Essa escala se mostrou significativamente correlacionada com a nota de conhecimento, identificada por meio da correlação não paramétrica de Spearman, ainda que considerada fraca $(S=0,298, p=0,001)$.

A média geral de consumo sustentável, por sua vez, apresentou resultado variando de 3 a 10 , com média de 6,56, corroborando as afirmações de que existem mudanças comportamentais em curso em relação à intenção de consumo mais consciente (Afonso, Bornia, Echegaray \& Andrade, 2016), ainda que de forma modesta. Essa escala apresentou correlações significativas tanto com o saber o significado do selo quanto com a escala geral de julgamento dos selos, a primeira negativa e considerada fraca, com a correlação não paramétrica de Spearman $(S=-0,31, p=0,001)$ e a segunda considerada moderada, por meio da correlação paramétrica de Pearson $(P=0,537, p=0,000)$. Tal resultado sugere que há de fato maior conscientização, visto que a correlação positiva moderada entre consumo sustentável e julgamento dos selos mostra que quanto mais consciente o sujeito em relação a hábitos de consumo sustentável, existe uma tendência a melhor julgamento da adoção do selo. Por outro lado, a correlação negativa, ainda que fraca, entre consumo sustentável e saber o significado do selo indica que quanto menor o nível de conhecimento sobre práticas de consumo sustentável, mais o sujeito se julga conhecedor do significado dos selos, o que pode contribuir para a proliferação de práticas irresponsáveis de marketing verde, como o fenômeno do greenwashing.

\subsubsection{Análise unidimensional}

1) Primeiramente, buscou-se verificar as diferenças referentes à manipulação do selo, comparando os selos FSC $(n=74)$ e ECO $(n=64)$.

Em relação à percepção geral, não foram encontradas diferenças significativas entre os selos em relação à lembrança $(\mathrm{H} 1 \mathrm{la})$ e ao significado $(\mathrm{H} 1 \mathrm{C})$, verificadas por meio do teste não paramétrico de Mann-Whitney. Resultado diferente foi encontrado referente ao conhecimento (H1b), cuja escala de nota de conhecimento apresentou diferenças significativas entre os selos, verificada por meio da análise não paramétrica Mann-Whitney $(U=1.320, p=0,001)$, com uma maior nota atribuída ao selo ECO (Mean rank $=75,6$, ) do que quando o selo era o FSC (Mean rank $=53,7)$. 
A escala geral de avaliação dos selos ( $\mathrm{H} 3 \mathrm{a}$ ) foi verificada por meio da análise paramétrica ANOVA, obtendo-se uma diferença significativa entre os selos $(F(1,122)=5,6, p=0,02)$, também com melhor avaliação quando o selo era o $\mathrm{ECO}(M=5,71, \mathrm{DP}=1,65)$, do que quando era o $\mathrm{FSC}(\mathrm{M}=4,97$, $\mathrm{DP}=1,78)$. Por outro lado, em relação aos atributos verdes relacionados à marca $(\mathrm{H} 3 \mathrm{~b})$, também se obteve diferença significativa com o teste não paramétrico de Mann-Whitney $(U=2.034, p=0,02)$, com uma maior atribuição verde quando o selo era o FSC (Mean rank $=64,29)$ do que quando era o ECO (Mean rank=52,38).

Conforme esperado diante dos resultados apresentados, a variável de manipulação apresentou correlação significativa com três variáveis, analisada por meio da correlação de Spearman, sendo duas delas negativas e a outra positiva: nota conhecimento $(S=-0,309, p=0,000)$, avaliação geral dos selos $(S=-0,23, p=0,01)$ e atributo verde $(S=0,213, p=0,21)$.

Ou seja, em síntese, observou-se uma melhor avaliação do selo falso e desconhecido tanto na nota de conhecimento (H1b) quanto na escala geral de avaliação dos selos (H3a), o que justifica a correlação negativa encontrada. Esse resultado abre margem para se questionar a eficácia da prática de adoção de selos verdes, bem como indica a possibilidade de ações de greenwashing, visto a incapacidade dos participantes de diferenciar um selo verdadeiro e conhecido de um falso. A melhor avaliação do selo verdadeiro e positivo só se deu em relação aos atributos verdes relacionados à marca (suporte à $\mathrm{H} 3 \mathrm{~b}$ ), o que explica a correlação positiva identificada e respalda a importância da divulgação e utilização de selos verdes nos produtos, conforme defendido pela literatura (Campanhol, Andrade \& Alves, 2003).

2) Para verificar a influência do perfil de consumo sustentável, optou-se por categorizar esse perfil em pouco sustentável $(n=37)$ e muito sustentável $(n=40)$.

A percepção geral não mostrou diferenças significativas entre os perfis de consumo em relação à lembrança do selo $(\mathrm{H} 2 \mathrm{a})$ e ao conhecimento $(\mathrm{H} 2 \mathrm{~b})$, verificadas pelo teste não paramétrico de Mann-Whitney. Referente ao significado $(\mathrm{H} 2 \mathrm{C})$, houve uma divergência, encontrando diferença significativa em relação ao saber o que significa, verificada por meio da análise não paramétrica Mann-Whitney $(U=407, p=0,003)$, com um resultado melhor quando o perfil era pouco sustentável (Mean rank=32,37,) do que quando era muito sustentável (Mean rank=29,81).

A escala geral de avaliação dos selos $(\mathrm{H} 4 \mathrm{a})$ também apresentou diferenças significativas entre os perfis, analisada por meio do teste paramétrico ANOVA $(F(1,76)=46,76, p=0,000)$, com uma melhor avaliação dos perfis muito sustentáveis $(M=6,55, D P=1,44)$ em comparação aos pouco sustentáveis $(M=4,19, D P=1,59)$. Os atributos verdes relacionados à marca ( $\mathrm{H} 4 \mathrm{~b}$ ) não mostraram diferenças significativas entre os perfis com o teste não paramétrico de Mann-Whitney.

Tabela 4:

Teste de hipóteses - Análise unidimensional

\begin{tabular}{|l|c|c|}
\hline \multicolumn{1}{|c|}{ Hipóteses do Estudo } & Selo & Perfil \\
\hline $\begin{array}{l}\text { H1 - A percepção geral dos consumidores [ (a) lembrança de ter visto, } \\
\text { (b) conhecimento e (c) saber o significado] é influenciada pela } \\
\text { popularidade e veracidade dos selos }\end{array}$ & $\begin{array}{c}\text { Significativ } \\
\text { parcial, } \\
\text { mas } \\
\text { inverso (b) }\end{array}$ & - \\
\hline $\begin{array}{l}\text { H2 - A percepção geral dos consumidores [ (a) lembrança de ter visto, } \\
\text { (b) conhecimento e (c) saber o significado] é influenciada pelo seu } \\
\text { próprio perfil de consumo sustentável. }\end{array}$ & $\begin{array}{c}\text { Signicativ } \\
\text { a parcial, } \\
\text { mas } \\
\text { inverso } \\
\text { (c1) }\end{array}$ \\
\hline $\begin{array}{l}\text { H3a - A adoção de selos verdes influencia em uma melhor avaliação } \\
\text { geral acerca dessa prática, especialmente quando o selo verde é } \\
\text { popular e veraz. }\end{array}$ & $\begin{array}{c}\text { Significativ } \\
\text { a mas } \\
\text { inverso }\end{array}$ & - \\
\hline $\begin{array}{l}\text { H3b - A adoção de selos verdes influencia em uma melhor avaliação } \\
\text { verde da marca que adota selo verde, especialmente quando o selo } \\
\text { verde é popular e veraz. }\end{array}$ & $\begin{array}{c}\text { Suportada } \\
\text { H4a - O perfil de consumo sustentável influencia uma melhor avaliação } \\
\text { geral acerca da prática de adoção de selos verdes, especialmente } \\
\text { quando perfil é bastante sustentável. }\end{array}$ & - \\
\hline $\begin{array}{l}\text { H4b - O perfil de consumo sustentável influencia em uma melhor } \\
\text { avaliação verde da marca que adota selo verde, especialmente quando } \\
\text { o perfil é bastante sustentável. }\end{array}$ & \begin{tabular}{c} 
Suportada \\
\hline
\end{tabular} & $\begin{array}{c}\text { Não } \\
\text { significativ } \\
\text { a }\end{array}$ \\
\hline
\end{tabular}

Fonte: Elaboração própria. 
De forma similar ao selo, conforme esperado diante dos resultados supracitados, a variável de perfil de consumo apresentou correlação significativa com duas variáveis, verificada pela correlação de Spearman, uma negativa e outra positiva: sabe o que significa $(S=-0,357, p=0,002)$ e avaliação geral dos selos $(S=0,651, p=0,000)$.

Em suma, os resultados indicam que houve uma melhor avaliação do perfil pouco sustentável quando se perguntou se eles sabiam o que o selo significava (H1c), justificando a correlação negativa entre essas variáveis. Entretanto, essa resposta se mostrou equivocada quando comparada à baixa taxa de evocação forçada desse significado, enfraquecendo, assim, sua validade. Por outro lado, conforme esperado, o perfil muito sustentável avaliou melhor a escala geral de avaliação de selos (suporte à $\mathrm{H4}$ ), evidenciado pela correlação forte, indicando a existência de alguma influência do nível de consciência do sujeito quanto as práticas de consumo sobre a avaliação do selo, o que pode transbordar de alguma forma sobre a imagem da empresa (Campos et al., 2013).

\subsubsection{Análise bidimensional}

Em relação à lembrança do selo $(\mathrm{H} 1 \mathrm{a}$ e $\mathrm{H} 2 \mathrm{a})$ e ao conhecimento ( $\mathrm{H} 1 \mathrm{~b}$ e $\mathrm{H} 2 \mathrm{~b}$ ), não foram encontradas diferenças significativas entre os grupos por meio do teste não paramétrico de Kruskal Wallis. Diferença significativa foi encontrada referente ao significado ( $\mathrm{H} 1 \mathrm{c} \mathrm{e} \mathrm{H2c}$ ), verificada por meio da análise não paramétrica Kruskal Wallis $(Q=9,948, p=0,019)$. Utilizando o teste de MannWhitney como post hoc $(U=79,5, p=0,015)$, identificou-se que a diferença ocorreu entre os grupos (2)Selo ECO com muito sustentável (Mean rank=13,47) e (3)Selo FSC com pouco sustentável (Mean rank $=21,82$ ). Ou seja, nota-se que tanto o selo falso como o perfil muito sustentável influenciaram à percepção geral dos participantes, suportando $\mathrm{H} 2 \mathrm{C}$, mas encontrando resultado inverso em relação à H1C.

Em relação à avaliação geral dos selos verdes, foram encontradas diferenças significativas entre quatro tratamentos, verificadas por meio da análise paramétrica ANOVA $(F(3,73)=19,41$, $p=0,000)$. Essas diferenças foram exploradas pelo teste de Bonferroni. Primeiro, o grupo (2)Selo ECO com muito sustentável foi preponderante perante ambos os grupos (1)Selo ECO com pouco sustentável $(M=2,578, S D=0,501, p=0,000)$ e (3)Selo FSC com pouco sustentável $(M=3,335$, $\mathrm{SD}=0,482, p=0,000)$. Essa preponderância também se mostrou para o grupo (4)Selo FSC com muito sustentável frente a ambos os grupos (1)Selo ECO com pouco sustentável $(M=1,496, S D=0,467$, $p=0,012)$ e (3)Selo FSC com pouco sustentável $(M=2,253, S D=0,447, p=0,000)$.

Ou seja, os resultados indicam a predominância de influência do perfil de consumo sustentável sobre a avaliação dos selos, indicando que quanto mais consciente o perfil de consumo maior a possibilidade de uma avaliação positiva sobre o selo, independentemente do selo em questão (H4a). No entanto, merece atenção o fato de o selo falso ter sido melhor avaliado também entre o grupo com maior perfil de consumo sustentável, sugerindo novamente uma possível incapacidade de diferenciação (Deus, Felizola \& Silva, 2010).

Analisando também os dois fatores identificados nessa escala de avaliação geral dos selos verdes, novamente diferenças significativas foram observadas pela análise paramétrica ANOVA, tanto em relação ao primeiro fator $(F(3,69)=4,64, p=0,005)$ como relacionado ao segundo fator $(F(3,69)=4,64, p=0,005)$. Ao explorar essas diferenças por meio do teste de Bonferroni, observou-se no primeiro fator (comportamento de consumo em geral) uma superioridade do grupo (1)Selo ECO com pouco sustentável perante ambos os grupos (2)Selo ECO com muito sustentável ( $M=32,743$, $S D=10,378, p=0,014)$ e (4)Selo FSC com muito sustentável $(M=32,837, S D=9,699, p=0,007)$. Para o segundo fator (postura do consumidor, em particular), houve predominância do grupo (2)Selo ECO com muito sustentável frente a ambos os grupos (3)Selo FSC com pouco sustentável ( $M=1,175$, $S D=0,327, p=0,004)$ e (4) Selo FSC com muito sustentável ( $M=0,839, S D=0,305, p=0,045)$.

Isso significa que, para o comportamento de consumo em geral, o perfil de consumo sustentável também tem maior influência, mas de maneira negativa, sugerindo que, de fato, existe uma maior intenção declarada pelo perfil de consumo sustentável, mas que não se traduz em práticas de maior engajamento coletivo no comportamento de consumo. Para o fator de postura do consumidor, em particular, por sua vez, o perfil de consumo sustentável se mostrou positivamente influente, além de ressaltar também a influência do selo, maior para o selo falso e nada conhecido.

Os atributos verdes relacionados à marca ( $\mathrm{H} 3 \mathrm{~b}$ e $\mathrm{H} 4 \mathrm{~b}$ ) não mostraram diferenças significativas entre os grupos, verificadas com o teste não paramétrico de Kruskal Wallis. 
Tabela 5:

Teste de hipóteses - Análise bidimensional

\begin{tabular}{|l|c|c|}
\hline $\begin{array}{l}\text { H1 - A percepção geral dos consumidores [ (a) lembrança } \\
\text { de ter visto, (b) conhecimento e (c) saber o significado] é } \\
\text { influenciada pela popularidade e veracidade dos selos. }\end{array}$ & $\begin{array}{c}\text { Significativa parcial, } \\
\text { mas inverso (b) }\end{array}$ & $\begin{array}{c}\text { Significativa parcial, } \\
\text { mas inverso (c) }\end{array}$ \\
\hline $\begin{array}{l}\text { H2 - A percepção geral dos consumidores [ (a) lembrança } \\
\text { de ter visto, (b) conhecimento e (c) saber o significado] é } \\
\text { influenciada pelo seu próprio perfil de consumo sustentável. }\end{array}$ & $\begin{array}{c}\text { Significativa parcial, } \\
\text { mas inverso (c) }\end{array}$ & Suportada parcial (c) \\
\hline $\begin{array}{l}\text { H3a - A adoção de selos verdes influencia em uma melhor } \\
\text { avaliação geral acerca dessa prática, especialmente quando } \\
\text { o selo verde é popular e veraz. }\end{array}$ & $\begin{array}{c}\text { Significativa mas } \\
\text { inverso }\end{array}$ & Significativa mas \\
inverso
\end{tabular}

Fonte: Elaboração própria.

\section{Conclusões e Recomendações}

O trabalho teve como objetivo analisar a percepção dos consumidores acerca dos selos verdes de acordo com o quão conhecidos esses selos são e segundo seu próprio perfil de consumo verde. No intuito de testar as quatro hipóteses levantadas, dois experimentos foram realizados, analisando-se os resultados de forma unidimensional e bidimensional. Em ambas as análises, o primeiro experimento conseguiu apenas suporte parcial a uma das hipóteses, de maneira unidimensional. Dessa forma, um segundo experimento foi conduzido, conseguindo suportes parciais a duas hipóteses e encontrando, ainda, diferenças significativas inversas em outras hipóteses. Foi o caso também do não suporte à hipótese, uma de maneira unidimensional e duas de maneira bidimensional.

Nesse sentido, quatro principais discussões puderam ser depreendidas desse esforço. Primeiro, sugere-se uma preocupante possibilidade de greenwashing, em dois sentidos. Observou-se que a menção da palavra ECO como nome do selo falso adotado no primeiro experimento, pela mera associação aos aspectos ecológicos, mostrou maior capacidade de influência nos participantes, inclusive de maneira mais incisiva do que um selo há mais de 20 anos em atuação no mercado. Essa influência foi corroborada pela ausência de efeitos quando da adoção do selo no primeiro experimento, que foi criado por meio de uma combinação aleatória de sorteio de letras. Ou seja, parece ser mais importante um selo que faça clara menção aos aspectos ambientais, do que um que acumule tanto tempo de atuação, independentemente de sua veracidade e popularidade.

Além disso, notou-se que a mera inserção do escrito certificação ambiental, subjacente ao selo verde, ausente no primeiro experimento e presente no segundo, mostrou-se mais importante como fator de influência do que o selo em si. Novamente, a clara menção aos aspectos ambientais, mesmo que com um dizer aleatório, sugere ser mais importante do que o selo verde, sua credibilidade e veracidade. Sendo assim, não só se evidencia a possibilidade de greenwashing, como se chama a atenção para a potencialização de disseminação dessa prática. Isso se torna de especial preocupação quando se lembra que a fiscalização dos apelos verdes utilizados nos anúncios publicitários ainda ocorre de maneira muito incipiente, tanto no Brasil quanto no mundo.

Esses resultados, por sua vez, sugerem a ineficácia da prática de adoção de selos verdes pelas empresas, que enfrenta claras dificuldades para conseguir comunicar seu diferencial atrelado à causa e, assim, beneficiar-se de alguma vantagem competitiva que pudesse ser oriunda de um apelo verde. Essa ineficácia consegue, inclusive, influenciar o comportamento de consumidores que se dizem mais sustentáveis. Depreende-se, portanto, que os selos podem ser importantes mecanismos de comunicação de práticas verdes das empresas em relação a seus produtos, mas que não representam influência comercial significativa sobre a intenção de compra do consumidor.

Apesar dos resultados obtidos, tendo em vista os suportes parciais encontrados, devem ser consideradas as limitações desse estudo, especialmente aquelas referentes ao procedimento metodológico. Sendo assim, ressalta-se que se trata de um estudo exploratório, cuja amostra foi 
escolhida por conveniência, com procedimento elaborado pelos autores e materiais específicos desenvolvidos propriamente para esses fins, seja em relação aos selos, às embalagens ou ao produto escolhido, ou mesmo ao instrumento de pesquisa. Como o estudo teve como foco a validade interna, os resultados encontrados são limitados ao contexto específico de aplicação desse estudo.

Nesse sentido, recomendam-se para estudos futuros que novas variáveis sejam incluídas ou diferentes manipulações sejam empregadas, como, por exemplo, a questão do envolvimento do consumidor e o nível de relevância de um produto. Sendo assim, pode-se testar a influência da adoção dos selos verdes e do perfil de consumo sustentável em relação a um produto de alto valor agregado, como um automóvel. Possíveis diferenças em relação a essas variáveis também podem ser testadas ao considerar públicos distintos, analisando-se co-variáveis como gênero, idade e renda.

\section{Notas}

1. Os autores agradecem a dois avaliadores anônimos que se dispuseram gentil e voluntariamente a contribuir de maneira significativa com melhoria do presente trabalho.

\section{Referências}

Afonso, A. C. (2010). O consumidor verde: perfil e comportamento de compra. Tese de Doutorado, Instituto Superior de Economia e Gestão.

Afonso, M. H., Bornia, A. C., Echegaray, F., \& Andrade, D. F. (2016). Comportamento de Consumo Sustentável: mensuração com o uso da Teoria da Resposta ao Item. Gestão.Org - Revista Eletrônica de Gestão Organizacional, 14(Edição Especial), pp. 16-29.

Alderson, W. (1957). Marketing Behavior and Executive Action. Homewood: Richard D. Irwin.

Andreoli, T. P., Crespo, A., \& Minciotti, S. A. (2016). Por que não estamos falando do greenwashing? Uma pesquisa bibliométrica acerca do tema. XIX SEMEAD - Seminários em Administração (p. sp). São Paulo/SP: FEA/USP.

Antunes, D., Santos, A. J., \& Hurtado, A. L. (2015). A comunicação da ACV: a necessidade de diretrizes para evitar o Greenwashing. Espacios, 36(5), p. sp.

Assadourian, E. (2010). Ascensão e Queda das Culturas de Consumo. Em W. INSTITUTE, Estado do Mundo 2010: estado do consumo e o consumo sustentável. Salvador: Uma Ed.

Bedante, G. N. (2004). A Influência da Consciência Ambiental e das Atitudes em Relação ao Consumo Sustentável na Intenção de Compra de Produtos Ecologicamente Embalados. Dissertação de Mestrado, Universidade Federal do Rio Grande do Sul, Programa de Pós-Graduação em Administração, Porto Alegre.

Braga Junior, S. S., Merlo, E. M., \& Silva, D. (2016). "Não acredito em consumo verde". O reflexo do ceticismo no comportamento de compra do consumidor. Revista de Gestão Social e Ambiental, 10(3), pp. 02-15.

Braga Junior, S. S., Silva, D., \& Moretti, S. L. (2011). Fatores de influência no consumo "verde": um estudo sobre o comportamento de compra no setor supermercadista. REMark: Revista Brasileira de Marketing, 10(1), pp. 151-176.

Budinsky, J., \& Bryant, S. (2013). It's not easy being green: the grenwashing of environmental discourses in advertising. Canadian Journal of Communication, 38(2), pp. 207-226.

Cabestré, S. A., Graziadei, T. M., \& Polesel Filho, P. (2008). Comunicção Estratégica, Sustentabilidade e Responsabilidade Socioambiental: um estudo destacando os aspectos teóricos conceituais e práticos. Conexão - Comunicação e Cultura, 7(13), pp. 39-58.

Campanhol, E. M., Andrade, P., \& Alves, M. C. (2003). Rotulagem Ambiental: barreira ou oportunidade estratégica. REA - Revista Eletrônica de Administração, 2(2), p. sp.

Campos, S. A., Palma, L. S., Neutzling, D. M., Zucato, L. C., \& Slongo, L. A. (2013). A comunicação verde fala por si: efeitos na identidade corporativa e propensão de compra. RECADM - Revista Eletrônica de Ciência Administrativa, 12(2), pp. 191-204.

Carson, R. (1962). Silent Spring. Boston: Houghton Mifflin. 
Consumo Sustentável. (2005). Manual de Educação. Brasília: Consumers International/MMA/MEC/IDEC.

Corrêa, L. B. (1998). Comércio e Meio Ambiente: atuação diplomática brasileira em relação ao selo verde. Instituto Rio Branco, Centro de Estudos Estratégicos. Brasília: Coleção Curso de Altos Estudos do Instituto Rio Branco.

Côrtes, P. L., \& Moretti, S. L. (2013). Consumo Verde: um estudo transcultural sobre crenças, preocupações e atitudes ambientais. REMark - Revista Brasileira de Marketing, 12(3), pp. 45-76.

Deus, N. S., Felizola, M. P., \& Silva, C. E. (2010). O Consumidor Socioambiental e seu Comportamento frente aos Selos de Produtos Responsáveis. RBDAM - Revista Brasileira de Administração Científica, $1(1)$, pp. 32-54.

Guimarães, C., Viana, L. S., \& Costa, P. H. (2015). Os Desafios da Consciência Ambiental: o marketing verde em questão. C@LEA - Cadernos de Aulas do LEA, spe(4),pp. 94-104.

Hair Jr, J. F. (2009). Análise Multivariada de Dados. Porto Alegre: Bookman.

Henion, K. E., \& Kinnear, T. C. (1976). Ecological Marketing. Columbus: American Marketing Association.

Hur, W.-M., Kim, Y., \& Park, K. (2013). Assessing the Effects of Perceived Value and Satisfaction on Customer Loyalty: a 'green' perspective. Corporate Social Responsibility and Environmental Management, 20(3), pp. 146-156.

Joshi, Y., \& Rahman, Z. (2015). Factors Affecting Green Purchase Behaviour and Future Research Directions. International Strategic Management Review, 3(1-2), pp. 128-143.

Katrandjiev, H. (2016). Ecological Marketing, Green Marketing, Sustainable Marketing: Synonyms or an Evolution of Ideas? Economic Alternatives, spe(1), pp. 71-82.

Lopes, V. N., \& Pacagnan, M. N. (2014). Marketing Verde e Práticas Socioambientais nas Indústrias do Paraná. Revista de Administração, 49(1), pp. 116-128.

Paavola, J. (2001). Towards Sustainabble Consumption: economics and ethical concerns for the environmental in consumer choices. Review of Social Economics, 59(2), pp. 227-248.

Paço, A. M., Raposo, M. L., \& Leal Filho, W. (2009). Identifying the Green Consumer: a segmentation study. Journal of Targeting, Measurement and Analysis for Marketing, 17(1), pp. 17-25.

Paço, A., Alves, H., Shiel, C., \& Leal Filho, W. (2013). Development of a green consumer behaviour model. International Journal of Consumer Studies, 37(4), pp. 414-421.

Peattie, K. (2001). Towards Sustainability: the third age of green marketing. The Marketing Review, 2(2), pp. 129-146.

Pereira, S. J., \& Ayrosa, E. A. (2004). Atitudes Relativas a Marcas e Argumentos Ecológicos: um estudo experimental. Gestão.Org - Revista Eletrônica de Gestão Organizacional, 2(2), pp. 134-145.

Polonsky, M. J. (1994). An Introduction to Green Marketing. Electronic Green Journal, 1(2), p. Article 3.

Roberts, A. J. (1996). Green Consumer in the 1990s: profile and implications for advertising. Journal of Business Research, 36(3), pp. 217-231.

Silva, A. M., \& Lopes, W. G. (2014). Virtudes e Falácias do Marketing Verde e Consumo Sustentável: a percepção de servidores públicos de instituições de ensino em Teresina, Piauí. REDE - Revista Eletrônica do PRODEMA, 8(2), pp. 77-91.

Silva, M. E. (2012). Consumo Sustentável: a articulação de um constructo sob a perspectiva do desenvolvimento sustentável. RECADM - Revista Eletrônica de Ciência Administrativa, 11(2), pp. 217-232.

Silva, M. E., \& Gómez, C. R. (2010). Consumo Consciente: o papel contributivo da educação. REUNA, 15(3), pp. 43-54.

Silva, M. E., \& Nascimento, L. F. (2015). Atuação Responsável ou Jogo de Mercado? Entendendo a relação empresa-mídia para a efetivação do consumo sustentável. Rev. Adm. UFSM, 8(1), pp. 73-88.

Silva, M. E., Oliveira, A. P., \& Gómez, C. R. (2013). Indicadores de Consumo Consciente: uma avaliação do Recifense sob a ótica do consumo sustentável. RECADM - Revista Eletrônica de Ciência Administrativa, 12(2), pp. 173-190. 
Slater, D. (2002). Cultura do Consumo e Modernidade. São Paulo: Nobel.

Suki, N. M. (2013). Green Awareness Effects on Consumers' Purchasing Decision: some insights from Malaysia. ljaps, 9(2), pp. 49-63. 